\title{
A large cirsoid aneurysm of the scalp associated with epilepsy
}

\author{
S. MOHANTY1 AND C. J. RAO \\ From the Section of Neurosurgery, Department of Surgery, Institute of Medical Sciences, \\ Banaras Hindu University, India
}

SYNOPSIS A large cirsoid aneurysm of the scalp that was present since birth in a $1 \frac{1}{2}$ year old baby is reported. For six months the patient had been suffering from generalized seizures and mental retardation. After excision of the aneurysm, the patient became seizure free.

Cirsoid aneurysms of the scalp are rare. They are usually of either congenital or traumatic origin. The congenital type may be present at birth and be associated with a red or purple birthmark (Khodadal, 1971). Oldfield and Addison (1962) have grouped the scalp cirsoid aneurysms into small, moderate, and large. The present report describes a patient with a large cirsoid aneurysm that had been present since birth. The swelling progressively increased in size and the patient developed mental retardation associated with cerebral seizures.

\section{CASE REPORT}

A female baby (Hospital No: 15220) aged $1 \frac{1}{2}$ years was admitted on 30 September 1975 with a history of progressively increasing swelling on the right side of the head since birth. She had two attacks of generalized seizures within three months before admission. Although milestones of development were normal up to 1 year of age, for the last six months the parents had noticed retardation. On examination she was a healthy, playful baby without any focal neurological deficit. The fundi were normal. Local examination revealed a $10 \mathrm{~cm} \times 6 \mathrm{~cm} \times 6 \mathrm{~cm}$ soft compressible swelling with a thrill and bruit, situated on the right parietotemporo-occipital region (Fig. 1). There was visible pulsation of the swelling and large pulsating arteries and veins entering and leaving the swelling. Some of the branches of the superficial temporal

${ }^{1}$ Requests for reprints to: Dr S. Mohanty, Department of Surgery, Institute of Medical Sciences, Banaras Hindu University, Varanasi221005, India.

(Accepted 6 May 1976.) artery of the opposite side also supplied the swelling. The ipsilateral carotid artery was enlarged and, on compression, the bruit and radiography of the skull were normal. The ipsilateral superficial temporal artery was punctured and angiography of the swelling performed. It revealed a lake of blood and arteriovenous fistulae. No intracranial shunting was observed (Fig. 2).

The external carotid artery was ligated at its origin from the common carotid artery. Immediately after the ligation, the bruit and pulsation of the swelling markedly reduced. There was slight diminution in size of the swelling. A week later, tl:e superficial temporal artery of the opposite side was ligated and a large scalp flap raised. Fine emissary veins at the base of the swelling were sealed by bonewax. Arteriovenous fistulae with a large pool of blood were excised from the under surface of the scalp. Blood loss was immediately replaced. Postoperatively the patient's recovery was uneventful. There has been no seizure to the time of reporting and development appears to be satisfactory.

\section{COMMENT}

Large cirsoid aneurysm of the scalp producing cerebral seizures is a rare condition. Relative ischaemia of the cerebrum due to extracranial shunting of common carotid blood flow was probably responsible for the cerebral seizures and mental retardation. Complete excision of the malformed mass of vessels was followed by cessation of seizures and improved mental development. 


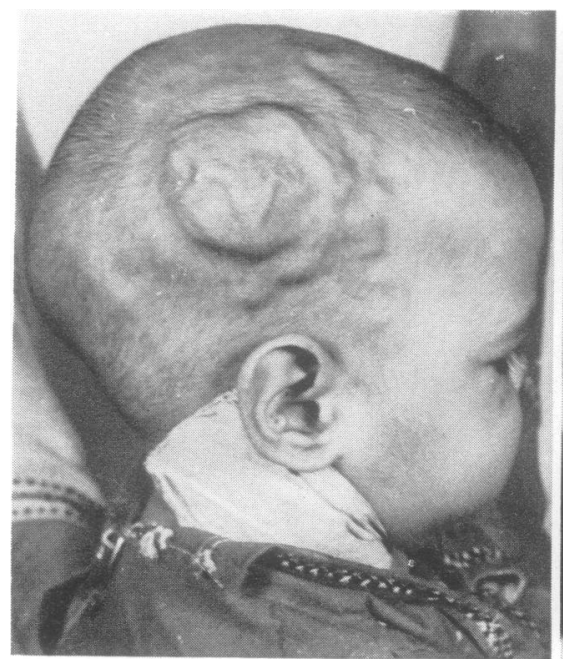

FIG. 1 Cirsoid aneurysm of scalp.

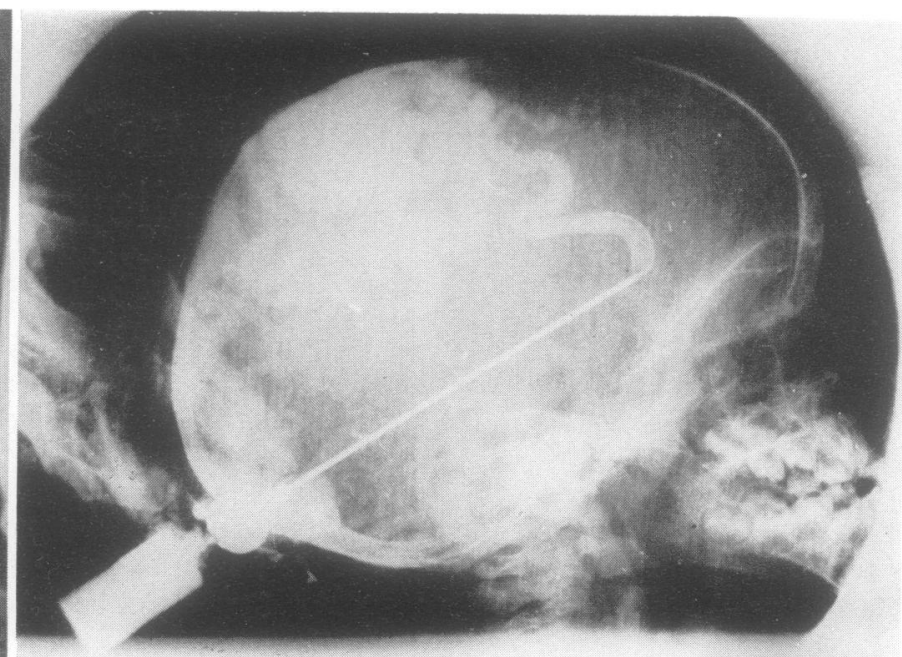

FIG. 2 Angiogram showing the lake of blood and arteriovenous fistulae.
We are grateful to Major General L. K. Anantanarayanan, Superintendent, S. S. Hospital, Banaras Hindu University, for his kind permission to publish this case report.

\section{REFERENCES}

Khodadal, G. (1971). Familial cirsoid aneurysm of the scalp. Journal of Neurology, Neurosurgery, and Psychiatry, 34, 664-667.

Oldfield, M. C., and Addison, N. V. (1962). Cirsoid aneurysms of the scalp. British Medical Journal, 2, 23. 